\title{
STEVEN LEVISTSKY \& MAURICIO ZAVALETA, ¿POR QUÉ NO HAY PARTIDOS POLÍTICOS EN EL PERÚ? EDITORIAL PLANETA PERÚ S. A. 2019, 82 PP.
}

\author{
STEVEN LEVISTSKY \& MAURICIO ZAVALETA, WHY ARE THERE NO \\ POLITICAL PARTIES IN PERU? EDITORIAL PLANETA PERÚ S. A. 2019, \\ 82 PP.
}

Sonia Beatriz Munaris Parco ${ }^{*}$

soniamunaris28@hotmail.com

${ }^{1}$ Institución Educativa "Nuestra Señora de Fátima”, Ayacucho, Perú

*Correspondencia: Sonia Beatriz Munaris Parco. Email: soniamunaris28@hotmail.com

Recibido: 14.11.19 | Aprobado: 04.12.19

\section{RESUMEN}

Bajo el anuncio de Perú Breve de la Editorial Planeta, presentan el trabajo seductor de Steven Levistsky \& Mauricio Zavaleta en un escenario de agitación política en el Perú y Sudamérica, donde los gobernantes no gozan de simpatía de la población por falta de sostenibilidad ideológica que debería tener todo partido político.

Palabras clave: Política, corrupción.

\section{ABSTRACT}

Under the banner of Peru Brief from Editorial Planeta, they present the seductive work of Steven Levistsky \& Mauricio Zavaleta in a scenario of political turmoil in Peru and South America, where the rulers do not enjoy the sympathy of the population due to lack of ideological sustainability that should have every political party.

Keywords: Politics, corruption. 
Bajo el anuncio de Perú Breve de la Editorial Planeta, presentan el trabajo seductor de Steven Levistsky \& Mauricio Zavaleta en un escenario de agitación política en el Perú y Sudamérica, donde los gobernantes no gozan de simpatía de la población por falta de sostenibilidad ideológica que debería tener todo partido político. El prefacio con el título: El trásfuga y su circunstancia de Alberto Vergara resume el contenido de este libro, que además dibuja nuestra vivencia como electores en cada campaña electoral. La política peruana, tiene un símil con las gangas del mercado informal: "Como el ambulante que busca cada día una esquina donde ofrecer su mercancía, el político nacional ansía alguna locomotora para la próxima elección” (p.9). En estas condiciones el político peruano, busca la mejor oferta de puesto para candidatear con una chequera bajo la manga. En un extremo desesperado, aterrizan en universidades-partidos, otros usufructúan los medios de comunicación y de esta forma alquilan a sus eventuales electores.

Quedaron rezagados los debates ideológicos de partidos políticos institucionalizados, de secretarías generales con personería a nivel nacional y sus congresos partidarios para elegir quién lo representará en las contiendas electorales de turno. César Hildebrandt resume muy bien el escenario político de la década de los '70, en su libro Cambio de palabras, cuando concluyó una entrevista periodística a 15 figuras de la política peruana a mencionar: Víctor Raúl Haya de la Torre, Jorge del Prado, Juan Velasco Alvarado, Luis Miró Quesada de la Guerra, Armando Villanueva, Andrés Townsend Ezcurra, Enrique Chirinos Soto, Hugo Blanco Galdós para su trabajo periodístico en la revista más importante de esa época Caretas. Termina el libro Hildebrandt con 10 entrevistas a políticos importantes en la década de los '80 como: Alfonso Barrantes Lingán, Luis Alberto Sánchez, Juan Gonzalo Rose, Fernando Belaunde Terry, Luis Bedoya Reyes, Pablo Macera, Javier Valle Riestra y Mario Vargas Llosa. En este trabajo se evidencia la calidad académica y política de personajes que simbolizan a un partido político institucionalizado, fundamentando sus posiciones ideológicas con bases científicas sociales. La década de los setenta vencidos por la dictadura militar de Juan Velasco Alvarado, fue un quiebre de la política peruana que, aún mantenía los debates ideológicos partidarios post-dictadura militar, Velasco defendía su golpe militar denunciando: "La revolución se ha dado el gusto de hacer las transformaciones que no hicieron los civiles. Los civiles tuvieron 150 años el Gobierno y no las hicieron. Por eso, es que la Fuerza Armada tuvo que hacer la revolución" (Hildebrandt, 2018, p.105). Las pugnas políticas entre militares y civiles, también es parte de la historia política peruana que concluirá, actualmente en proyectos personales para llegar al poder sin importar los medios con las cuales esté sustentado.

Levistsky \& Zavaleta plasman el prólogo a esta edición en un contexto ad hoc de cambios estructurales de la política peruana en una época vergonzosa para la generación centennials y millennial que no vivenciaron la efervescencia de luchas ideológicas partidarias. La política peruana, no tiene organizaciones sostenibles en el tiempo, no tienen proyecto político, ni partidario que les otorgue credibilidad ideológica. Las organizaciones sociales que por mucho tiempo les sirvieron de base, fueron languideciendo por el conflicto armado en el Perú. Sus representantes terminaron cambiando de partido político o transfuguismo, por encontrar un lugar y número privilegiado en los proyectos políticos personalistas de los empresarios exitosos, que llegaron ser presidentes del Perú. Lo mismo 
ocurre en las elecciones regionales, porque sus protagonistas políticos, transitaron por diferentes partidos políticos para llegar al poder. En similar sentido los que más pierden son los electores; puesto que, los candidatos escogen al que tiene mayor simpatía o carisma a su interés personal partidario, no evalúan los planes de trabajo político de los aspirantes al poder. Ingresamos a la versión peruana de la modernidad líquida, vida líquida avizorado por Zygmunt Bauman en su fase práctica: "Este nuevo programa público, aún a la espera de políticas críticas públicas, está emergiendo juntamente con la versión "liquificada" de la moderna condición humana y en particular, en vísperas de la "individualización” de las tareas de vida que surgen de esa condición" (2015, p.45). Es una forma perfecta de olvidarse de las tradiciones partidarias de la institucionalización para suplir con proyectos personales de cómo llegar al gobierno en su etapa regional y nacional.

“(...) más del 70 por cierto de la oferta partidaria estaba conformada por outsiders sin experiencia previa o políticos venidos de otras tiendas" (p.16). Ahí se suman algunos partidos políticos tradicionales, conformando la coalición con los autodenominados independientes, donde buscan un espacio acomodaticio para cautivar a los electores cándidos. Levistsky \& Zavaleta destacan la actuación del fujimorismo, Fuerza Popular que es la única agrupación política que puede apelar a una identidad partidaria, esta organización hizo alianzas con los sectores conservadores para fortalecer sus bases de militancia. El sustento económico que permite mantenerlos en la palestra política son sus integrantes que, más de la mitad de los congresistas de Fuerza Popular son empresarios, dueños de negocios o gerentes comerciales que se ubican como los privilegiados de la lista electoral. Consecuentemente, fueron los financistas directos de las campañas multimillonarias y algunas prebendas a favor del núcleo duro del fujimorismo que se ubica en el sector menesteroso del ciudadano peruano. Meléndez aporta con su investigación sobre el colapso partidario: "Perú carece de militantes partidarios en el sentido convencional del término, porque los vínculos programáticos que los agrupaban colapsaron" (2019, p.15). Remarca su trabajo en dos etapas: de partidos políticos en el siglo XX del aprismo y antiaprismo, el siglo XXI el fujimorismo y al antifujimorismo. Las teorías políticas perdieron su epicentro de aportar a la democracia, por lo menos existiendo dos partidos políticos equilibrando el poder, nuestra realidad es la supuesta independencia de partidos, en el fondo con intereses personales y proyectos familiares.

En la introducción, enfatizan que la mayoría de los partidos políticos son independientes que en cada elección crean su propia lista o negocian un puesto en la de otros. La más conocida son las coaliciones de independientes o listas de invitados, una vez terminada la elección desaparecen. Levistsky \& Zavaleta analizan el sistema de partidos políticos a finales de la década de 1980 y comienzos de la siguiente, bajo una crisis hiperinflacionaria y de la devastadora insurgencia senderista. Los partidos políticos que predominaron en el tiempo como: Alianza Popular Revolucionaria Americana, Partido Popular Cristiano, Acción Popular e Izquierda Unida decayeron en 1995, sumando un apenas 6 por ciento de electores, este colapso producto del outsider de Alberto Fujimori. "En cada elección fue creando un nuevo vehículo personalista: Cambio 90 en 1990, Nueva Mayoría en 1992 y 1995, Vamos Vecino en 1998 y Perú 2000 en el 2000" (p.25). Esta situación ha cesado la construcción de partidos políticos, abriendo camino a candidatos con proyectos personales. Consecuentemente, los movimientos regionales no 
contribuyeron a la reconstrucción de los partidos. Las coordinaciones para lograr una formación partidaria han fracaso, estos movimientos regionales, también tiene sus propios proyectos personales en contraposición de los partidos nacionales. Cada elecciones regionales y municipales se conforman una serie de partidos independientes con fines de ocupar la gobernación regional o la alcaldía municipal, dentro de las provinciales, aún existen otros micro partidos independientes con miras al gobierno municipal distrital.

Una vez fracasado los partidos políticos, muchos candidatos compran su lugar en las elecciones parlamentarias buscando la mejor oferta electoral. Un político ambicioso constantemente negocia su filiación partidaria; puesto que, en cada elección varía su popularidad y sostenibilidad en el tiempo. Levistsky \& Zavaleta enumeran varios políticos nacionales y regionales que tuvieron filiaciones con diversos movimientos independientes. El interés de los líderes políticos es captar personajes que puedan sumar en la campaña, con dinero o en su defecto con electores por su popularidad. Es un equipo de personas que desean ganar el mando del gobierno para sus intereses personales, no importa su filiación política, lo importante es que aporte económicamente o con electores identificados con el personaje. La estrategia perfecta para ganar asentimiento a un proyecto personal es el antiestablishment capitalizados por los outsiders exitosos.

Transcurrieron aproximadamente casi un cuarto de siglo después del colapso de los partidos políticos, pero aún no se han construido auténticos partidos políticos: "El caso peruano sugiere que la democracia y la competencia electoral por sí solas no generan suficientes incentivos para la formación de partidos" (p.43). A esta situación se suman los diseños electorales que no regulan un proceso ordenado y estructurado de las reglas electorales, no incentivan a la formación de partidos políticos estructurados con bases y militancias. Levistsky \& Zavaleta detallan varios movimientos políticos independentistas que surgieron con fines electorales, sin necesidad de pertenecer a un partido político constituido. Esa independencia partidaria en esencia es free agency destinado a las coaliciones, transfuguismos que se difundieron ampliamente en la década de 1990, consecuentemente su institucionalización informal. "Este proceso de aprendizaje se inició con la victoria del presentador televisivo Ricardo Belmont en la elección a la alcaldía de Lima en 1989, y fue posteriormente reforzada por la victoria presidencial de Fujimori en $1990 ”$ (p.49). Este escenario permite a los interesados en llegar a las gobernaciones, que no es necesario tener una marca partidaria para llegar a la presidencia, Fujimori lo ha demostrado con su antecesor Belmont.

Otra de las formas de hacer política en el Perú es recorrer a las nuevas técnicas como fundar un sustituto ideológico, está las empresas individuales de éxito de los políticos. Se suman la regencia de los medios de comunicación, especialmente en las elecciones regionales donde fundar una radio emisora es rédito electoral seguro. Por último, otra estrategia alternativa es buscar personajes famosos que no tengan vinculación con la política. "En el 2014 Yamila Osorio, una exreina de belleza, fue elegida presidenta regional de la importante región sureña de Arequipa" (p.58). En esta situación los partidos políticos tradicionales no cuentan con un aparato de marca empresarial, ni personal de las celebridades para llegar a los electores con eficiencia. Esta limitación favorece a los outsiders que poseen sustitutos partidarios. En el Perú los eslóganes de las campañas son importantes, pues direccionan la ruta de un político con intereses personales, nunca 
anuncian su autoría, ya que mayormente corresponde a un académico reconocido: "Como es propio de la política peruana, generan partidos o movimientos ad hoc para cada elección, en los que el candidato está establecido aún antes de que el propio movimiento exista" (Vergara, 2018, p.151). Este detalle no es supervisado por los entes electorales por su complicada estructura de la elección de bases de cada partido político.

Con el título, especial de La paradoja fujimorista: ¿un caso excepcional de construcción partidaria? Levistsky \& Zavaleta dedican especial atención al fujimorismo. Es un recorrido sobre el período fujimorista en el Perú, su caída y su permanencia en el escenario político con una marca naciente. Analizan la situación de Fujimori, de su actitud renuente en formar un partido político, en algunas ocasiones desarrolló esa formación partidaria con Absalón Vásquez con Vamos Vecino con fines de las elecciones municipales. La mejor antípoda para construir adeptos electores de fujimoristas duros, es exponer la sensación de injusticia a la población, así como las más grandes eventualidades de la vida. Posteriormente la situación fue desastrosa para los fujimoristas, que fueron juzgados por actos de corrupción y de lesa humanidad. Los intentos de formar un partido político como: "El fujimorismo comenzó a asumir una forma de tipo partidario en el 2005, cuando desde el exterior Fujimori creó Sí Cumple, con miras a retornar al Perú a postular a la presidencia en el 2006" (p.67). Las antiguas formaciones de las bases fujimoristas, hicieron una movilización de la maquinaria votante para lograr su retorno. Terminan el análisis del movimiento independentista de los Fujimori en la escena política, que no es muy clara en su continuación o en su defecto sería: "De este modo, un posible escenario sería algo semejante a la Unión Nacional Odriista (ONU), el partido del exdictador Manuel Odría, ...pero que se debilitó y eventualmente desapareció después de su muerte" (p.69). La situación de los Fujimori, termine en las condiciones de Odría, puesto que, sus personajes representativos fueron amateurs políticos vulnerables a las deserciones en el futuro.

Levistsky \& Zavaleta concluyen que los partidos políticos en el Perú lograrían su arraigo con el presupuesto público en sus campañas electorales, restructurando el aparato del sistema electoral. Cuando no exista condiciones pertinentes para el control y fortalecimiento de los partidos políticos: “(...) el colapso partidario podría en realidad tener un efecto Humpty Dumpty: una vez que los partidos desaparecen y los políticos encuentran los medios para ganar elecciones, pero sin ellos, toda la ingeniería electoral del mundo sería insuficiente para reconstruirlos" (p.73). Es un análisis minucioso, en un trabajo bien resumido que dibuja la realidad peruana y el entorno latinoamericano, su lectura es recomendable y de obligatoriedad para entender la situación política en el mundo actual. También, Vergara concluye con un análisis minucioso en sus diferentes artículos periodísticos compilado en un libro: "Y, como en el país, las discusiones ideológicas aburren; como en el resto de partidos, los profesionales de éxito no se acercan a militar; como en nuestros ciudadanos, el achoramiento da la hora; y, como en la sociedad, la ley es débil y el mandamás, robusto" (2018, p.140). Las apreciaciones no se equivocan, son políticos aprovechando el caos a falta de una línea política institucionalizada. 


\section{REFERENCIAS BIBLIOGRÁFICAS}

Bauman, Z. (2000). Modernidad líquida. Retrieved from https:/ / ebookcentral.proquest.com

Hildebrandt, C. (2018). Cambio de palabras. Lima: DEBATE.

Meléndez, C. (2019). El mal menor. Vinculos políticos en el Perú posterior al colapso del sistema de partidos. Lima: IEP Instituto de Estudios Peruanos.

Vergara, A. (2018). Ciudadanos sin república. De la precariedad institucional al descalabro político. Lima: Planeta.

\section{CITAR COMO:}

Munaris Parco, S. B. (2019). Steven Levistsky \& amp; Mauricio Zavaleta, ¿Por qué no hay partidos políticos en el Perú? Editorial Planeta Perú S. A. 2019, 82 pp. Puriq, 1(02), 181-186. https://doi.org/10.37073/puriq.1.02.36 